\title{
Laboratory studies of the aqueous-phase oxidation of polyols: submicron particles vs. bulk aqueous solution
}

\author{
K. E. Daumit, A. J. Carrasquillo, J. F. Hunter, and J. H. Kroll \\ Department of Civil and Environmental Engineering, Massachusetts Institute of Technology, Cambridge, MA 02139, USA \\ Correspondence to: J. H. Kroll (jhkroll@mit.edu)
}

Received: 19 April 2014 - Published in Atmos. Chem. Phys. Discuss.: 26 May 2014

Revised: 2 September 2014 - Accepted: 9 September 2014 - Published: 14 October 2014

\begin{abstract}
Oxidation in the atmospheric aqueous phase (cloud droplets and deliquesced particles) has received recent attention as a potential pathway for the formation of highly oxidized organic aerosol. Most laboratory studies of aqueous-phase oxidation, however, are carried out in bulk solutions rather than aqueous droplets. Here we describe experiments in which aqueous oxidation of polyols (water-soluble species with chemical formula $\mathrm{C}_{n} \mathrm{H}_{2 n+2} \mathrm{O}_{n}$ ) is carried out within submicron particles in an environmental chamber, allowing for significant gas-particle partitioning of reactants, intermediates, and products. Dark Fenton chemistry is used as a source of hydroxyl radicals, and oxidation is monitored using a high-resolution aerosol mass spectrometer (AMS). Aqueous oxidation is rapid, and results in the formation of particulate oxalate; this is accompanied by substantial loss of carbon to the gas phase, indicating the formation of volatile products. Results are compared to those from analogous oxidation reactions carried out in bulk solution. The bulk-phase chemistry is similar to that in the particles, but with substantially less carbon loss. This is likely due to differences in partitioning of early-generation products, which evaporate out of the aqueous phase under chamber conditions (in which liquid water content is low), but remain in solution for further aqueous processing in the bulk phase. This work suggests that the product distributions from oxidation in aqueous aerosol may be substantially different from those in bulk oxidation experiments. This highlights the need for aqueous oxidation studies to be carried out under atmospherically relevant partitioning conditions, with liquid water contents mimicking those of cloud droplets or aqueous aerosol.
\end{abstract}

\section{Introduction}

A large fraction of atmospheric organic aerosol (OA) is known to be secondary in nature, formed by the oxidation and subsequent condensation of gas-phase precursors. However, the sources and formation mechanisms for the most oxidized fraction of OA remain highly uncertain. Ambient measurements indicate that the most highly oxidized OA has an average carbon oxidation state of between 0 and +1 (Daumit et al., 2013; Jimenez et al., 2009; Kroll et al., 2011) and can form rapidly over short timescales (approximately 1 to 3 days; Jimenez et al., 2009; Volkamer et al., 2006). However, the organic aerosol formed in laboratory studies is typically substantially less oxidized than this (Donahue et al., 2012; Heald et al., 2010; Kroll et al., 2011; Qi et al., 2010), and model studies generally have difficulty reproducing the same level of oxidation in such short timescales (Dzepina et al., 2009, 2011; Hodzic et al., 2010; Lee-Taylor et al., 2011).

Aqueous-phase oxidation has received considerable attention as a potential formation pathway for highly oxidized organic aerosol (Ervens et al., 2011; Lim et al., 2010). The oxidation of organic species in the aqueous phase has recently been investigated in the laboratory for a range of water-soluble species, including small carbonyls (Altieri et al., 2008; Carlton et al., 2007; Kirkland et al., 2013; Perri et al., 2009, 2010; Tan et al., 2009, 2010), isoprene and its oxidation products (Altieri et al., 2006; Kameel et al., 2013; Liu et al., 2012a; Renard et al., 2013; Zhang et al., 2010), and phenolic compounds (Smith et al., 2014; Sun et al., 2010). Such bulk-phase studies have clearly demonstrated that aqueous-phase oxidation, when it occurs, can lead to the rapid formation of highly oxidized organic species.

The importance of such oxidation processes relies critically on partitioning (Donahue et al., 2014): a compound 
will undergo aqueous-phase oxidation only if it is primarily partitioned to the atmospheric aqueous phase (cloud droplets or aqueous submicron particles), rather than the gas or condensed-organic phase. The partitioning between the gas and aqueous phases is determined by a compound's effective Henry's law constant $\left(H^{*}\right)$ (or alternatively its saturation vapor concentration over water $\left(c_{\mathrm{aq}}^{*}\right)$; Ervens et al., 2011), as well the liquid water content (LWC) of the air mass, as shown in Eq. (1):

$$
f_{\text {aq }}=\frac{(\mathrm{LWC}) H^{*} R T}{10^{12}+(\mathrm{LWC}) H^{*} R T}=\frac{\mathrm{LWC} / c_{\mathrm{aq}}^{*}}{1+\mathrm{LWC} / c_{\mathrm{aq}}^{*}},
$$

in which $f_{\text {aq }}$ is the equilibrium fraction in the aqueous phase, $\mathrm{LWC}$ is in units of $\mu \mathrm{g} \mathrm{m}^{-3}, H^{*}$ is in units of $\mathrm{Matm}^{-1}$, and $c_{\mathrm{aq}}^{*}$ is in units of $\mu \mathrm{g} \mathrm{m}^{-3}$ and is equal to $10^{12} H^{*-1} R^{-1} T^{-1}$ (where $R=0.0821 \mathrm{~L} \mathrm{~atm} \mathrm{~mol}^{-1} \mathrm{~K}^{-1}$ and $T$ is temperature in K). By Eq. (1), the partitioning of a single compound (with a fixed $H^{*}$ or $c_{\mathrm{aq}}^{*}$ ) can be very different for different values of LWC. Atmospheric LWCs can span many orders of magnitude, ranging from $\sim 1$ to $100 \mu \mathrm{g} \mathrm{m}^{-3}$ for aqueous aerosol, and $\sim 10^{5}$ to $10^{6} \mathrm{\mu g} \mathrm{m}^{-3}$ for cloud droplets (Ervens et al., 2011), while a bulk aqueous solution has a LWC on the order of $10^{12} \mu \mathrm{g} \mathrm{m}^{-3}$ (the density of water). Therefore, $f_{\mathrm{aq}}$ for a given compound will also vary by many orders of magnitude for these systems, as illustrated in Fig. 1. Many compounds that are considered to be "water-soluble" for bulk solutions $\left(H^{*}\right.$ of $\left.1-1000 \mathrm{M} \mathrm{atm}^{-1}\right)$ will not actually partition significantly into aqueous submicron particles, or even into cloud droplets. This could have an important influence on the resulting chemistry, and suggests that a bulk solution may not always accurately represent aqueous processing under atmospheric conditions.

Some recent bulk-solution experiments have begun to examine the role of gas-particle partitioning under lower-LWC conditions by atomizing or nebulizing the bulk aqueous solution as it undergoes aqueous oxidation (Lee et al., 2011a, b; 2012; Liu et al., 2012b; Ortiz-Montalvo et al., 2012; Zhao et al., 2012). While these studies do indeed show loss of the most volatile species formed, leaving behind only low-volatility condensed-phase products, the chemistry that forms these products still takes place in the bulk aqueous solution, with limited partitioning into the gas phase. To our knowledge, only two studies (Nguyen et al., 2013; Volkamer et al., 2009) have examined oxidation chemistry within aqueous droplets themselves, allowing for gas-particle partitioning that mimics what may occur in the atmosphere. These studies found enhanced uptake and aerosol yield from glyoxal (Volkamer et al., 2009) and glycolaldehyde (Nguyen et al., 2013) in the presence of aqueous submicron particles; results from these experiments have not been explicitly compared to those in which oxidation was carried out in bulk solutions.

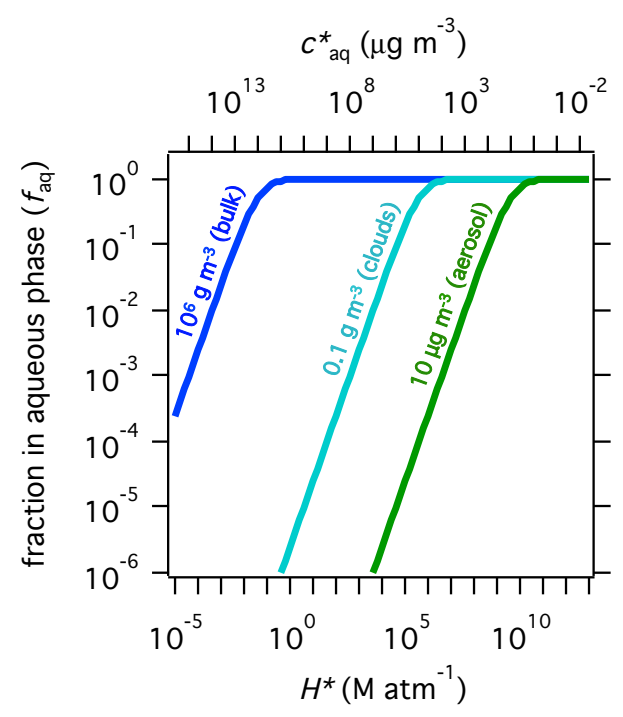

Figure 1. The fraction of a compound that will partition to the aqueous phase $\left(f_{\text {aq }}\right)$ as a function of its Henry's law constant, $H^{*}$ (or alternatively its saturation vapor concentration, $c_{\mathrm{aq}}^{*}$ ), and the liquid water content (LWC). Compounds with $0.1 \mathrm{M} \mathrm{atm}^{-1}<H^{*}<10^{9} \mathrm{M} \mathrm{atm}^{-1}$ will be primarily in the aqueous phase at bulk LWC (blue line), but primarily in the gas phase at aqueous aerosol LWC (green line). Cloud water (teal line) represents the intermediate case, with more partitioning into the aqueous phase than for aqueous particles, but still with far less than for a bulk aqueous solution.

Here we describe laboratory studies of the oxidation of water-soluble organic species in the aqueous phase, with experiments conducted both within bulk aqueous solutions and within submicron aqueous particles. The goal of these experiments is to compare the oxidation chemistry under very different partitioning conditions. We focus on the oxidation of polyols with the chemical formula $\mathrm{C}_{n} \mathrm{H}_{2 n+2} \mathrm{O}_{n}$ (with one hydroxyl group on each carbon atom). Polyols with four or more carbon atoms have exceedingly high values of $H^{*}$ (> $10^{16} \mathrm{M} \mathrm{atm}^{-1}$, Sander, 1999), ensuring they will be present in the aqueous phase even at the low LWC in our chamber; thus any observed partitioning will involve reaction intermediates and products only. To our knowledge, this work is the first direct comparison of aqueous oxidation in submicron particles and in bulk aqueous solution.

\section{Experimental methods}

Two sets of experiments are conducted: (1) bulk oxidation, in which reactions take place within a bulk aqueous solution of $\sim 0.5 \mathrm{~L}$ volume, and (2) chamber oxidation, in which reactions take place within submicron aqueous particles in an environmental chamber. Both sets of experiments use dark Fenton chemistry $\left(\mathrm{Fe}^{2+}\right.$ and hydrogen peroxide) as an aqueousphase source of oxidants. While there is some uncertainty as 
to the exact oxidant-forming mechanisms in Fenton systems, in part due to the complex iron speciation, it is likely that hydroxyl radicals $(\mathrm{OH})$ are the predominant oxidant formed in our experiments (Ma et al., 2006; Southworth and Voelker, 2003). $\mathrm{Fe}^{2+}$ reacts with hydrogen peroxide $\left(\mathrm{H}_{2} \mathrm{O}_{2}\right)$ to produce $\mathrm{OH}$ and $\mathrm{Fe}^{3+}$, which is subsequently converted back to $\mathrm{Fe}^{2+}$ via reaction with other species:

$\mathrm{Fe}^{2+}+\mathrm{H}_{2} \mathrm{O}_{2} \rightarrow \mathrm{Fe}^{3+}+\mathrm{HO}^{-}+\mathrm{OH}$,

$\mathrm{Fe}^{3+}+\mathrm{H}_{2} \mathrm{O}_{2} \rightarrow \mathrm{Fe}^{2+}+\mathrm{HO}_{2}+\mathrm{H}^{+}$,

$\mathrm{Fe}^{3+}+\mathrm{HO}_{2} \rightarrow \mathrm{Fe}^{2+}+\mathrm{O}_{2}+\mathrm{H}^{+}$.

Alternatively, $\mathrm{Fe}^{3+}$ can form complexes with water or organic acids; these pathways compete with the regeneration of $\mathrm{Fe}^{2+}$ and can eventually slow the production of $\mathrm{OH}$ :

$\mathrm{Fe}^{3+}+\mathrm{H}_{2} \mathrm{O} \rightarrow \mathrm{Fe}(\mathrm{OH})^{2+}+\mathrm{H}^{+}$,

$\mathrm{Fe}^{3+}+\mathrm{L}^{-} \rightarrow \mathrm{Fe}(\mathrm{L})^{2+}(\mathrm{L}=$ organic ligand $)$.

A more detailed treatment of this chemistry is described elsewhere (Arakaki and Faust, 1998; Faust and Hoigne, 1990; Hoffmann et al., 1996; Ma et al., 2006; Nguyen et al., 2013; Ou et al., 2008). In both sets of experiments, we start with a mixture of a polyol and $\mathrm{Fe}^{2+}$, and initiate the oxidation chemistry with the addition of $\mathrm{H}_{2} \mathrm{O}_{2}$. The use of Fenton chemistry to initiate oxidation within aqueous submicron particles was first demonstrated in a recent glycolaldehyde uptake study by Nguyen et al. (2013); the present experiments differ from that work in that we focus on dark Fenton chemistry, using the addition of $\mathrm{H}_{2} \mathrm{O}_{2}$ rather than exposure to UV lights to initiate the reaction.

\subsection{Bulk aqueous oxidation}

For bulk oxidation experiments, the general technique of Lee et al. (2011a) is used, in which an atomizer serves both as the reactor containing the aqueous solution and as the method for aerosolizing the solution, enabling online analysis by aerosol instrumentation. Figure 2 a shows a simple schematic of the experimental setup. Reactions are carried out in a $1 \mathrm{~L}$ borosilicate reaction bottle, and the solution is continuously atomized using a constant output atomizer (TSI, model 3076) with a backing pressure of $\sim 30$ psi of pure compressed air (Aadco 737-13A/C with methane reactor), giving 2.5-3 LPM aerosol output flow. The atomizer output is passed through an empty $1 \mathrm{~L}$ bottle to remove excess liquid water, then through a diffusion dryer, and finally into the aerosol instruments, described in Sect. 2.3.

A major difference between the present experiments and previous bulk oxidation experiments (Lee et al., 2011a, b, 2012; Liu et al., 2012b; Ortiz-Montalvo et al., 2012; Zhao et al., 2012) is the oxidation scheme: here $\mathrm{OH}$ radicals are generated via dark Fenton chemistry rather than photolysis of hydrogen peroxide, avoiding the use of $254 \mathrm{~nm}$ lights. The initial atomization solution contains iron(II) sulfate heptahydrate $(99+\%)$ and a polyol (glycerol, $99.5+\%$, erythritol,
$99+\%$, adonitol $99+\%$, mannitol $98+\%$, or volemitol, all Sigma-Aldrich) fully dissolved in Milli-Q water; concentrations are given in Table 1. Prior to $\mathrm{H}_{2} \mathrm{O}_{2}$ addition, this solution is atomized into the aerosol mass spectrometer (AMS) (see below) to characterize the reactants and ensure they are inert with respect to each other. To initiate Fenton chemistry, hydrogen peroxide (30\% w/w in water, Alfa Aesar) is added and the solution is shaken to facilitate mixing. After $\sim 3 \mathrm{~h}$, once the reaction appears to have gone to completion, the solution is exposed to UV light for additional oxidation (via photo-Fenton chemistry) and/or direct photolysis, using four external black lights (Sylvania BL-350 ECO, output 300$400 \mathrm{~nm}$ ). Photo-Fenton reactions regenerate $\mathrm{Fe}^{2+}$ and can produce additional $\mathrm{OH}$ :

$\mathrm{Fe}^{3+}\left(\mathrm{OH}^{-}\right)+\mathrm{h} v \rightarrow \mathrm{Fe}^{2+}+\mathrm{OH}$,

$\mathrm{Fe}^{3+}\left(\mathrm{L}^{-}\right)+\mathrm{h} v \rightarrow \mathrm{Fe}^{2+}+\mathrm{L}$.

\subsection{Chamber oxidation}

Chamber experiments are conducted to allow for aqueous oxidation in submicron particles, providing partitioning conditions representative of deliquesced atmospheric aerosol. The chamber oxidation setup is shown in Fig. 2b. The MIT chamber is a $7.5 \mathrm{~m}^{3}$ Teflon $(0.13 \mathrm{~mm}$ PFA) bag within a temperature-controlled environmental room. Two banks of 24 black lights (Sylvania BL-350 ECO) on opposite sides of the chamber provide UV irradiation when needed. The chamber is run as a semi-batch reactor with 5 LPM pure air added to balance instrument sample flows. A fraction of this air is sent through a bubbler containing Milli-Q water in order to maintain a relative humidity of between 67 and $79 \%$, ensuring that all sulfate-containing particles are aqueous. Prior to reaction, seed particles composed of iron(II) sulfate $\left(\mathrm{FeSO}_{4}\right)$ and a polyol are introduced into the chamber via atomization. The liquid water content in the chamber is not directly measured, but is estimated to be in the range of $\sim 20$ to $\sim 150 \mu \mathrm{g} \mathrm{m}^{-3}$ prior to oxidation, based on concentrations of particulate water measured by the AMS. These values are broadly consistent with liquid water contents estimated by assuming the particles have a similar hygroscopic growth factor as particles of ammonium sulfate (Seinfeld and Pandis, 2006). Concentrations of the atomizer solution are given in Table 1; it should be noted that, within the aqueous particles themselves, concentrations will be substantially higher than these values, since the solution is concentrated upon atomization by a factor of $\sim 1000$ (based on measured mass loadings and estimated LWC).

Seed particles are allowed to mix in the chamber for $1 \mathrm{~h}$ prior to addition of $\mathrm{H}_{2} \mathrm{O}_{2}$, which initiates the reaction. $\mathrm{H}_{2} \mathrm{O}_{2}$ is not added directly to the atomizer solution, since this would initiate oxidation in the bulk solution prior to atomization, and so is instead introduced in the gas phase, from which it subsequently partitions into the aqueous phase. Gasphase $\mathrm{H}_{2} \mathrm{O}_{2}$ is introduced by sending 1-1.5 LPM air through 
Table 1. Initial concentrations of reactants in the atomizer solutions.

\begin{tabular}{|c|c|c|c|c|c|c|c|}
\hline \multicolumn{2}{|c|}{ Polyol precursor } & \multicolumn{3}{|c|}{ Bulk experiments } & \multicolumn{3}{|c|}{ Chamber experiments } \\
\hline $\begin{array}{l}\text { Name \& } \\
\text { formula }\end{array}$ & $\begin{array}{l}\text { Chemical } \\
\text { structure }\end{array}$ & $\begin{array}{c}\text { [Polyol] } \\
(\mathrm{mM})\end{array}$ & $\begin{array}{c}{\left[\mathrm{FeSO}_{4}\right]} \\
(\mathrm{mM})\end{array}$ & $\begin{array}{c}{\left[\mathrm{H}_{2} \mathrm{O}_{2}\right]} \\
(\mathrm{mM})\end{array}$ & $\begin{array}{c}{\text { [Polyol }]^{\mathrm{a}}}^{(\mathrm{mM})} \\
\quad\end{array}$ & $\begin{array}{l}{\left[\mathrm{FeSO}_{4}\right]^{\mathrm{a}}} \\
\quad(\mathrm{mM})\end{array}$ & $\begin{array}{c}{\left[\mathrm{H}_{2} \mathrm{O}_{2}\right]^{\mathrm{b}}} \\
(\mathrm{mM})\end{array}$ \\
\hline $\begin{array}{l}\text { Glycerol } \\
\left(\mathrm{C}_{3} \mathrm{H}_{8} \mathrm{O}_{3}\right)\end{array}$ & & 0.20 & 0.45 & 2.0 & 2.0 & 0.40 & 27 \\
\hline $\begin{array}{l}\text { Erythritol } \\
\left(\mathrm{C}_{4} \mathrm{H}_{10} \mathrm{O}_{4}\right)\end{array}$ & & 0.20 & 0.42 & 2.0 & 2.0 & 0.39 & 27 \\
\hline $\begin{array}{l}\text { Adonitol } \\
\left(\mathrm{C}_{5} \mathrm{H}_{12} \mathrm{O}_{5}\right)\end{array}$ & & 0.20 & 0.41 & 2.0 & 2.0 & 0.40 & 27 \\
\hline $\begin{array}{l}\text { Mannitol } \\
\left(\mathrm{C}_{6} \mathrm{H}_{14} \mathrm{O}_{6}\right)\end{array}$ & & 0.22 & 0.42 & 2.0 & 2.0 & 0.38 & 27 \\
\hline $\begin{array}{l}\text { Volemitol } \\
\left(\mathrm{C}_{7} \mathrm{H}_{16} \mathrm{O}_{7}\right)\end{array}$ & & 0.19 & 0.40 & 2.0 & 2.0 & 0.40 & 27 \\
\hline
\end{tabular}

\footnotetext{
a Initial concentrations in the atomizer solution; the aqueous particles themselves will be substantially more concentrated (by a factor of $\sim 1000$ ).

b Estimated concentrations within the particles, calculated by assuming full evaporation of $\mathrm{H}_{2} \mathrm{O}_{2}$ into the chamber, with Henry's law partitioning into the aqueous particles; these likely represent an upper limit.
}

a two-neck flask containing $6.0 \mu \mathrm{L}$ of $30 \%$ aqueous $\mathrm{H}_{2} \mathrm{O}_{2}$ solution and into the chamber via a Teflon line; full evaporation of the $\mathrm{H}_{2} \mathrm{O}_{2}$ takes approximately $30 \mathrm{~min}$. Assuming all the $\mathrm{H}_{2} \mathrm{O}_{2}$ enters the chamber, and partitions into the aqueous particles according to Henry's law (with $H^{*}=10^{5} \mathrm{M} \mathrm{atm}^{-1}$;

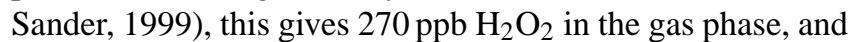
$27 \mathrm{mM}$ in the aqueous particles. This aqueous concentration is higher than in the bulk experiments, but the concentrations of $\mathrm{Fe}^{2+}$ and polyol are also higher in the particles than in the bulk solution. However, because some $\mathrm{H}_{2} \mathrm{O}_{2}$ is expected to be lost to surfaces, such as the Teflon inlet tubing and chamber walls, these $\mathrm{H}_{2} \mathrm{O}_{2}$ concentrations likely represent upper limits. After completion of the dark Fenton chemistry, the black lights are turned on for additional photolytic and/or oxidative chemistry, as in the bulk experiments. Under dark conditions, gas-phase oxidation is unlikely; however, during irradiation the photolysis of $\mathrm{H}_{2} \mathrm{O}_{2}$ will lead to the formation of some gas-phase $\mathrm{OH}$; as discussed below, this is unlikely to affect the observed chemistry.

\subsection{Aerosol analysis}

Aerosol size distribution, volume, and number density are monitored using a scanning mobility particle sizer (SMPS; TSI Inc.). Chemical composition of non-refractory particulate matter is measured using a high-resolution time-of-flight AMS (Aerodyne Research Inc.). This allows for the measurement of chemical families, such as total organic, sulfate, and ammonium (Canagaratna et al., 2007; DeCarlo et al., 2006), as well as elemental ratios of the organic species, most im- portantly oxygen-to-carbon $(\mathrm{O} / \mathrm{C})$ and hydrogen-to-carbon (H/C) (Aiken et al., 2007, 2008). All data reported here were taken with the instrument operated in $\mathrm{V}$ mode. Because the amount of sulfate per particle is constant, abundances of all reported ions and families are normalized to sulfate, accounting for possible changes in collection efficiency (CE), variations in atomizer output, dilution in the chamber or atomizer, and loss of particles to surfaces. Some sulfate signal $(10-25 \%)$ is measured in the "closed" mass spectra, suggesting that $\mathrm{FeSO}_{4}$ does not flash-vaporize at the temperature of the AMS vaporizer $\left(\sim 550-600^{\circ} \mathrm{C}\right)$. However, this fraction does not vary significantly over any experiment, suggesting the AMS "diff" signal is sufficient for this normalization. In most chamber experiments the aerosol is not sent through a dryer prior to analysis, though drying appears to have no effect on measured elemental ratios or sulfate-normalized concentrations. For chamber oxidation experiments, we also monitor temperature and relative humidity (Vaisala), $\mathrm{NO}_{\mathrm{x}}$ (Horiba Inc.), and ozone (2B Tech).

\section{Results and discussion}

A series of control experiments were carried out to verify that aqueous-phase, dark Fenton chemistry was indeed responsible for any chemistry observed. No reaction was observed between the polyols and $\mathrm{FeSO}_{4}$ in the absence of $\mathrm{H}_{2} \mathrm{O}_{2}$, nor between the polyols and $\mathrm{H}_{2} \mathrm{O}_{2}$ in the absence of $\mathrm{FeSO}_{4}$, confirming that both $\mathrm{Fe}^{2+}$ and $\mathrm{H}_{2} \mathrm{O}_{2}$ are necessary for oxidation to occur. Furthermore, no chemical changes were observed 

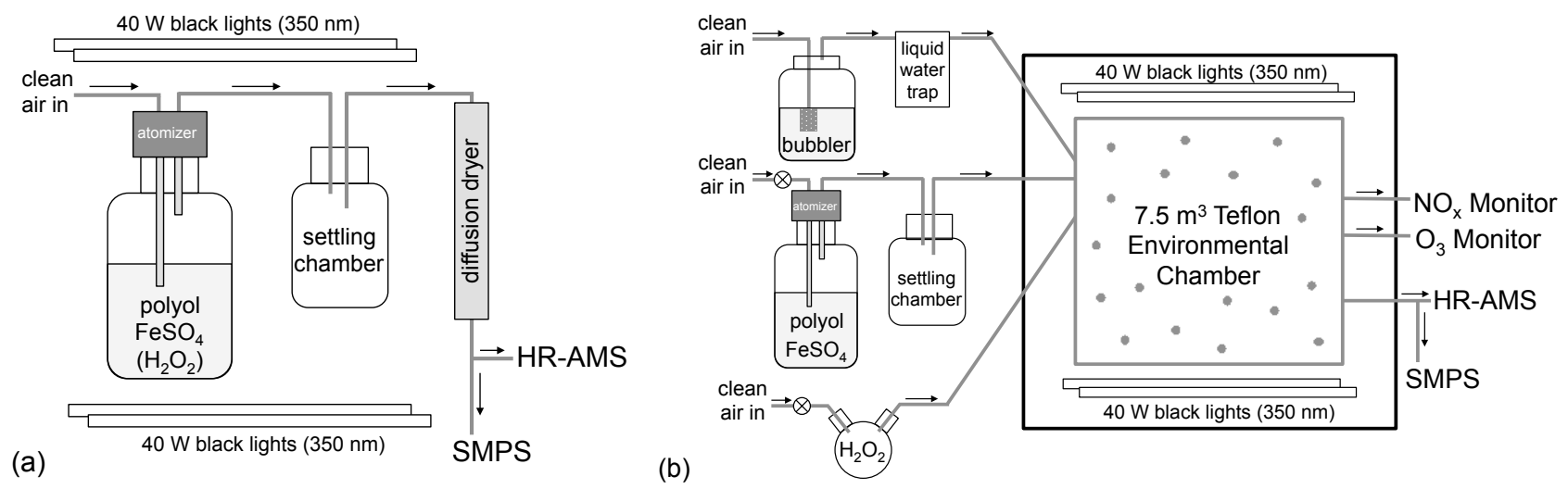

Figure 2. Experimental setup for (a) bulk experiments and (b) chamber experiments. The atomizer serves as a reactor for bulk oxidation but only as a source of aqueous particles for chamber oxidation. In the bulk experiments, the solution is continuously atomized, with $\mathrm{H}_{2} \mathrm{O}_{2}$ added after the polyol and $\mathrm{FeSO}_{4}$ have been sampled for $1 \mathrm{~h}$. In the chamber experiments, a solution containing the polyol and $\mathrm{FeSO}_{4}$ is atomized into the chamber for $1 \mathrm{~h}$, with gas-phase $\mathrm{H}_{2} \mathrm{O}_{2}$ introduced later via the two-neck flask. Humidified makeup air is continuously supplied to the chamber via the bubbler. While the focus of this work is dark Fenton chemistry, UV lights are turned on following oxidation in both setups in order to assess the photoreactivity of the reaction products.

upon addition of $\mathrm{H}_{2} \mathrm{O}_{2}$ or exposure to $\mathrm{UV}$ when a chamber experiment (using erythritol-FeSO 4 particles) was conducted under dry conditions $(\mathrm{RH}<4 \%)$. The sulfate-normalized organic signal gradually decayed over the course of this experiment, but this is likely a result of gradual evaporation of organic material as the chamber air is diluted. The lack of a reaction under such dry conditions confirms that the chemistry described below indeed takes place only in the aqueous phase.

\subsection{Bulk oxidation of erythritol}

Results for the bulk oxidation of erythritol $\left(\mathrm{C}_{4} \mathrm{H}_{10} \mathrm{O}_{4}\right)$ are shown in Fig. 3. Figure 3a shows the aerosol mass spectrum of the aqueous erythritol solution, taken over a $30 \mathrm{~min}$ period immediately prior to the addition of $\mathrm{H}_{2} \mathrm{O}_{2}$. Figure $3 \mathrm{~b}$ shows the time traces of key AMS ions and species (all normalized to sulfate). Once $\mathrm{H}_{2} \mathrm{O}_{2}$ is added, oxidation occurs immediately. Key ions associated with erythritol $(m / z 29,39,61,73$, 91) begin to decay rapidly, presumably by reaction with $\mathrm{OH}$. Using a $k_{\mathrm{OH}}$ of $1.9 \times 10^{9} \mathrm{M}^{-1} \mathrm{~s}^{-1}$ (Herrmann et al., 2010), this decay is consistent with an initial aqueous $\mathrm{OH}$ concentration of $4.8 \times 10^{-12} \mathrm{M}$, which is within an order of magnitude of the average $\mathrm{OH}$ concentrations estimated for ambient deliquesced particles (Herrmann et al., 2010). The OH concentration, estimated from the time dependence of the polyol concentration (see Supplement), drops over the course of the experiment, reaching a final $\mathrm{OH}$ exposure of $2.7 \times 10^{-9} \mathrm{M} \mathrm{s}$. Sulfate-normalized organic signal initially decreases, likely due to the formation and evaporation of compounds that are more volatile than erythritol, but then gradually rises, presumably from the addition of oxygen-containing functional groups that increase the molecular weight and reduce the volatility of the organic species. Ammonium $\left(\mathrm{NH}_{4}^{+}\right)$also rises, likely due to uptake of ammonia from the laboratory air; this is consistent with acidification of the solution, which is known to occur upon initiation of dark Fenton chemistry (Nguyen et al., 2013). This is accompanied by an instantaneous change in the appearance of the atomizer solution from colorless to yellow-orange, consistent with the formation of $\mathrm{Fe}(\mathrm{OH})^{2+}$ (Zuo and Hoigne, 1992).

Rapid growth of the $\mathrm{CO}_{2}^{+}$ion in the AMS is observed upon oxidation (Fig. 3b). This highly oxidized ion fragment, which typically indicates the presence of carboxylic acids, is the most abundant ion in the product mass spectra, shown in Fig. 3c. Figure $3 \mathrm{~d}$ shows the elemental ratios of the particulate organic species as a function of time; the rapid rise in $\mathrm{O} / \mathrm{C}$ and drop in $\mathrm{H} / \mathrm{C}$ upon addition of $\mathrm{H}_{2} \mathrm{O}_{2}$ is also consistent with rapid oxidation of the organic species. It should be noted that the initial $\mathrm{H} / \mathrm{C}$ and $\mathrm{O} / \mathrm{C}$ measured by the AMS do not match the true values for erythritol. This is a result of using the default elemental analysis correction factors, which have been determined empirically for an ensemble of species rather than individual compounds (Aiken et al., 2008); however, errors in the absolute elemental ratios are not expected to affect the observed trends in $\mathrm{H} / \mathrm{C}$ and $\mathrm{O} / \mathrm{C}$, nor the overall conclusions of this work. The rapid oxidation of dissolved organic species observed here is broadly consistent with the findings of other bulk oxidation studies (Altieri et al., 2006, 2008; Carlton et al., 2007; Kirkland et al., 2013; Lee et al., 2011a, b; 2012; Liu et al., 2012a; Perri et al., 2009; Sun et al., 2010; Tan et al., 2009, 2010; Zhang et al., 2010; Zhao et al., 2012).

The AMS mass spectrum of the oxidation products closely resembles that of oxalate $\left(\mathrm{C}_{2} \mathrm{O}_{4}^{-2}\right)$ (Mensah et al., 2011; Takegawa et al., 2007), which has been shown to be a major product in other aqueous-phase oxidation systems (Carlton et al., 2007; Perri et al., 2009; Tan et al., 2010). A pathway 

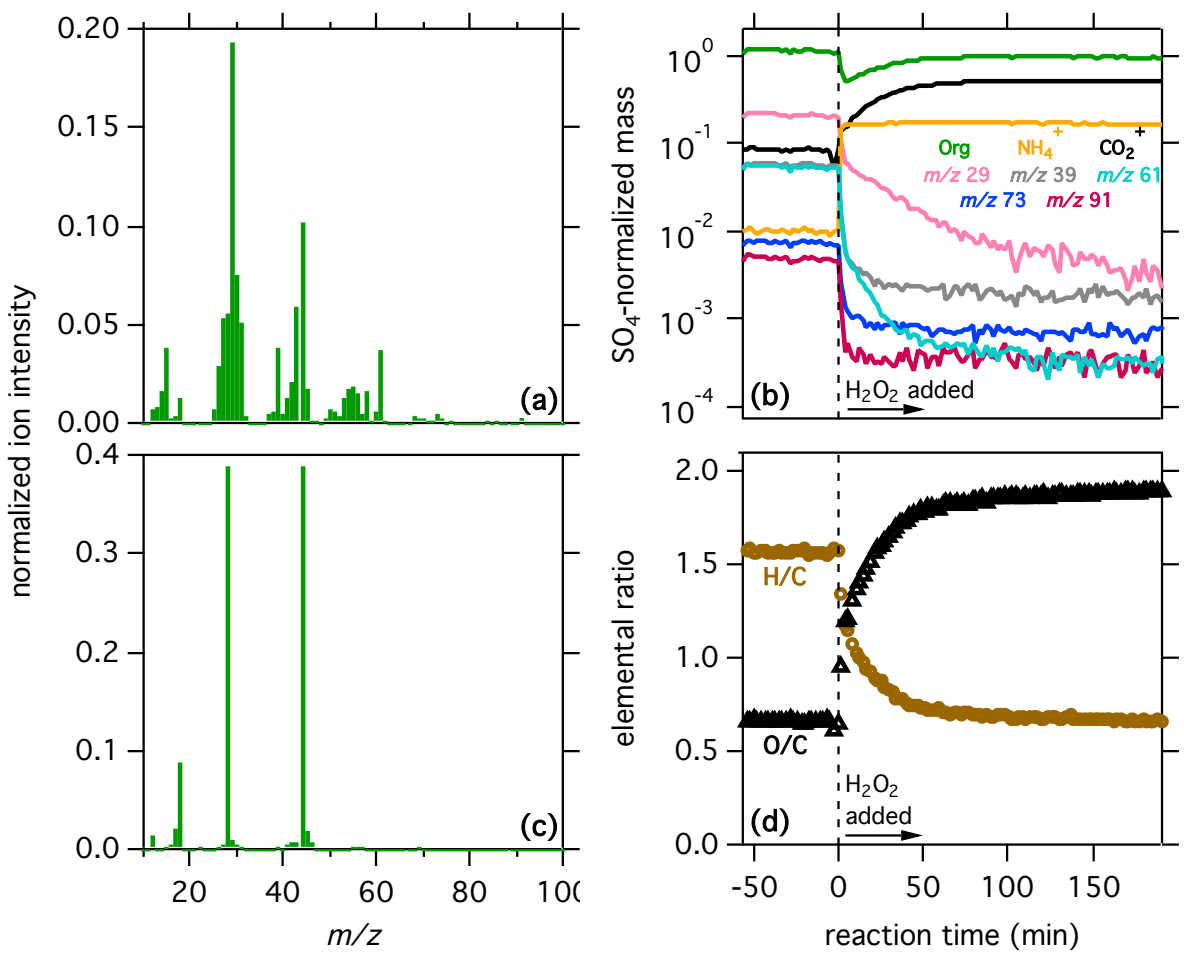

Figure 3. Results for the oxidation of erythritol within the bulk aqueous phase: (a) AMS spectra of unreacted erythritol; (b) sulfatenormalized mass concentrations of total organic $(\mathrm{Org})$, ammonium $\left(\mathrm{NH}_{4}^{+}\right), \mathrm{CO}_{2}^{+}$, and key ions associated with erythritol $(m / z 29,39$, $61,73,91)$ as a function of reaction time; (c) AMS spectra of oxidation products; and (d) oxygen-to-carbon and hydrogen-to-carbon ratios as a function of reaction time. Results in (a, c, d) are from high-resolution mass spectrometric analysis. All traces in (b) are from unit mass resolution, except $\mathrm{NH}_{4}^{+}$and $\mathrm{CO}_{2}^{+}$, which are high-resolution traces.

for the formation of oxalic acid from the aqueous oxidation of ethylene glycol (a C2 diol) has been shown by Tilgner and Herrmann (2010) and mechanisms for the formation of oxalic acid from larger diacids have been described by Ervens et al. (2004). We did not observe the formation of organonitrogen compounds, which were major reaction products in the uptake of glyoxal (Galloway et al., 2009; Nozière et al., 2009) and glycolaldehyde (Nguyen et al., 2013). In those studies, imidazoles and other $\mathrm{N}$-containing products were formed via nucleophilic attack of ketones and aldehydes by ammonia (Galloway et al., 2009; Nozière et al., 2009); such reactions are unlikely in the present system given the lack of carbonyl moieties in the polyols studied here.

The formation of oxalate (a highly oxidized C2 compound) from erythritol (a less oxidized $\mathrm{C} 4$ compound) likely occurs via multiple generations of oxidation. Individual intermediate ions (not shown) have significantly different temporal behavior, with some growing in and decaying before others, suggesting complex chemistry with intermediate products formed at different stages of oxidation. The varying rates of decay of erythritol ions in Fig. $3 b$ (e.g., $m / z 61$ vs. 91) provide further evidence that multigenerational oxidation is occurring in this system.
Upon exposure to UV, the organic ions decay still further, and the total organic signal decreases dramatically, in a short period of time (lifetime $\sim 36 \mathrm{~min}$; see Fig. S1a, Supplement). This is likely a result of either further oxidation by $\mathrm{OH}$ generated from photo-Fenton chemistry (Reaction R6) or direct photolysis (Reaction R7) to form small volatile species that cannot be detected by the AMS. This provides additional evidence for oxalate, since Fe(III) oxalato complexes are known to rapidly photolyze, a process that has been suggested as an important sink of atmospheric oxalate (Sorooshian et al., 2013). Given the abundance of iron in the system, our results suggest that the main condensed-phase oxidation product is oxalate, present as an iron oxalato complex.

\subsection{Chamber oxidation of erythritol}

Results for the oxidation of erythritol in aqueous particles in the chamber are shown in Fig. 4. As in the bulk experiment, dark Fenton chemistry within submicron particles in the chamber was found to lead to the rapid decay of erythritol and formation of oxidized products. A maximum $\mathrm{OH}$ concentration of $3.5 \times 10^{-12} \mathrm{M}$ is reached between 30 and $40 \mathrm{~min}$, and subsequently decreases to give a final $\mathrm{OH}$ exposure of $4 \times 10^{9} \mathrm{Ms}$; these values are similar (within a factor of 2) to those of the bulk experiments. 

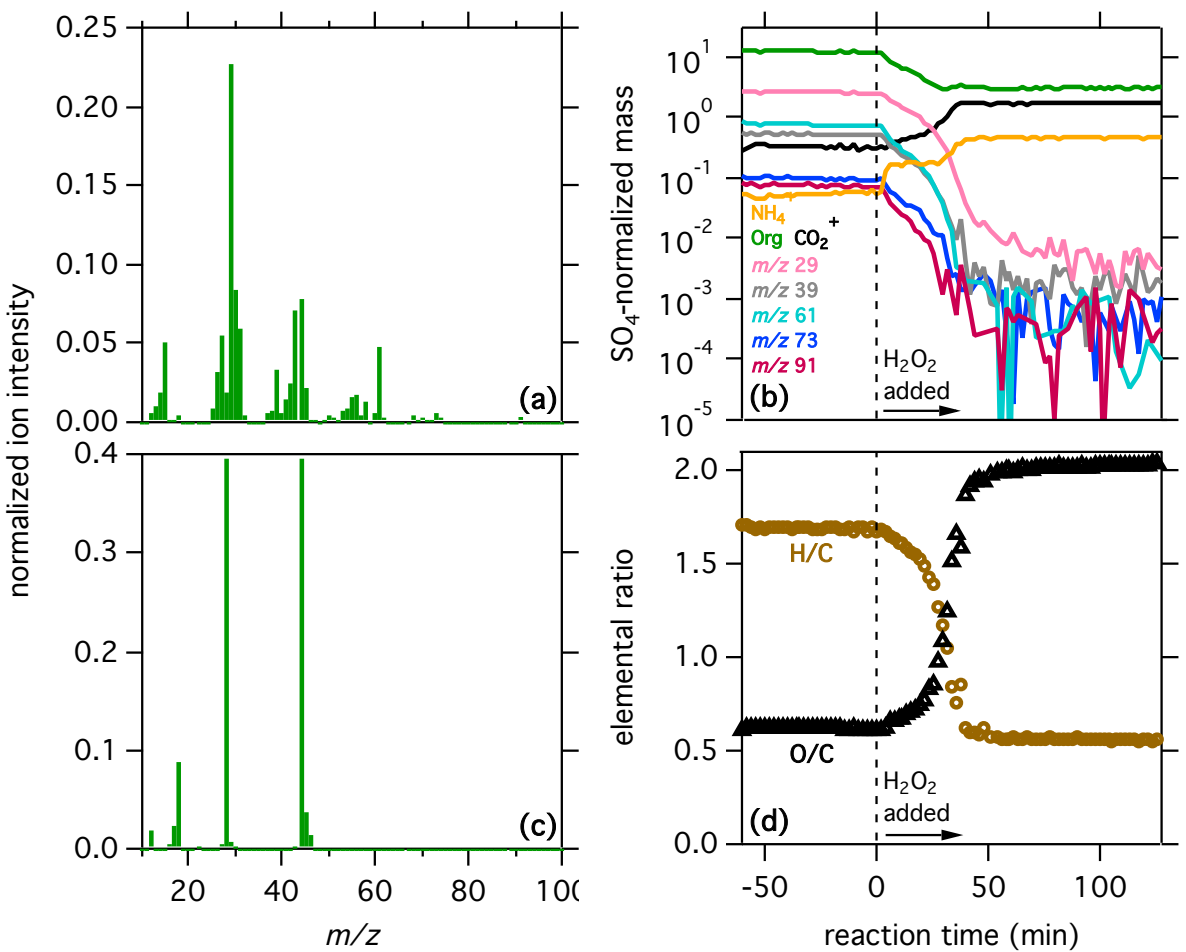

Figure 4. Same as Fig. 3, but for the oxidation of erythritol within submicron particles (chamber experiments): (a) AMS spectra of unreacted erythritol; (b) sulfate-normalized mass concentrations of total organic $(\mathrm{Org})$, ammonium $\left(\mathrm{NH}_{4}^{+}\right), \mathrm{CO}_{2}^{+}$, and key ions associated with erythritol $(m / z 29,39,61,73,91)$ as a function of reaction time; (c) AMS spectra of oxidation products; and (d) oxygen-to-carbon and hydrogen-to-carbon ratios as a function of reaction time.

The initial organic mass spectrum of unreacted erythritol in the chamber (Fig. 4a) closely matches that of erythritol in the bulk (Fig. 3a). The observed chemical changes in the two oxidation systems, as described by the time traces of key AMS ions from the chamber experiment (Fig. 4b), the product mass spectrum (Fig. 4c), and changes to $\mathrm{O} / \mathrm{C}$ and $\mathrm{H} / \mathrm{C}$ (Fig. 4d) are also similar to the bulk oxidation results. The primary difference is that the total organic signal decreases substantially more than in the bulk, with no subsequent increase, discussed in detail below. As in the bulk experiment, a rapid loss of organic mass is observed upon UV irradiation (Fig. S1b in the Supplement). This loss is unlikely to arise from oxidation by gas-phase $\mathrm{OH}$ (formed from $\mathrm{H}_{2} \mathrm{O}_{2}$ photolysis): the rapid loss of the organic species (lifetime $\sim 7 \mathrm{~min}$ ) would require an $\mathrm{OH}$ mixing ratio of $>6 \times 10^{7}$ molec $\mathrm{cm}^{-3}$ (assuming a $k_{\mathrm{OH}}$ of $<3 \times 10^{-11} \mathrm{~cm}^{3} \mathrm{molec}^{-1} \mathrm{~s}^{-1}$ ), far greater than can be produced by $\mathrm{H}_{2} \mathrm{O}_{2}$ photolysis. Instead, the rapid loss of organic mass probably arises from the direct photolysis of $\mathrm{Fe}$ (III) oxalato complexes, as in the bulk oxidation experiment.

Our finding of rapid oxidation by Fenton chemistry in the absence of UV light differs from the results of Nguyen et al. (2013), who found oxidation to occur only upon UV irradiation (photo-Fenton chemistry). In that work, the $\mathrm{H}_{2} \mathrm{O}_{2}$ was added directly to the atomizer solution (along with
$\mathrm{FeSO}_{4}$ ), and so dark Fenton chemistry may have gone to completion prior to the introduction of the organic species (glycolaldehyde) in the gas phase. By contrast, in the present experiments, $\mathrm{H}_{2} \mathrm{O}_{2}$ is added last, so that all $\mathrm{OH}$ is produced in the presence of the aerosol-phase organic compound. Because of such differences, and the differences in the organic species studied, results from the two chemical systems are difficult to compare directly. Nonetheless, our results are broadly consistent with those of Nguyen et al. (2013), in that they indicate that aqueous-phase oxidation in submicron particles can lead to the rapid formation of highly oxidized organic aerosol.

\subsection{Oxidation of other polyols}

Similar results are seen for the oxidation of most of the other polyols, in both the bulk phase and the chamber. The one exception is the oxidation of glycerol (a C3 polyol), which behaved differently in both the bulk and chamber experiments, presumably due to its high volatility. In the glycerol bulk experiments, the measured organic mass actually increased after oxidation, likely because the less volatile oxidation products evaporated less than glycerol upon atomization; in the chamber experiments, the LWC was too low for any measurable particulate glycerol. However, the C5-C7 polyols (adonitol, mannitol, and volemitol) all behaved similarly to 
erythritol upon oxidation, with decreases in the intensity of the polyol ions and $\mathrm{H} / \mathrm{C}$, increases in the $\mathrm{CO}_{2}^{+}$ion intensity and $\mathrm{O} / \mathrm{C}$, and product mass spectra resembling that of oxalate (Figs. S2-S4 in the Supplement). Estimated OH concentrations and exposures were also similar between the bulk and chamber cases (see Fig. S5 in the Supplement). As in the erythritol case, exposure to UV led to a rapid decrease in all organic ion signal intensity, as well as a decrease in total organic mass. In each case, the fraction of organic material remaining after oxidation was smaller for the chamber experiment than for the bulk experiment.

Shown in Fig. 5 is the fraction of carbon remaining in the condensed phase $\left(f_{\mathrm{C}}\right)$ after reaction in the bulk solution or deliquesced particles for each polyol (except glycerol, for which meaningful values of $f_{\mathrm{C}}$ could not be determined). This is calculated from the changes in organic mass concentration and elemental ratios:

$f_{\mathrm{C}}=\frac{[\mathrm{Org}]_{\mathrm{f}}}{[\mathrm{Org}]_{\mathrm{i}}} \frac{\left(16 \mathrm{O} / \mathrm{C}_{\mathrm{i}}+\mathrm{H} / \mathrm{C}_{\mathrm{i}}+12\right)}{\left(16 \mathrm{O} / \mathrm{C}_{\mathrm{f}}+\mathrm{H} / \mathrm{C}_{\mathrm{f}}+12\right)}$,

in which $[\mathrm{Org}]$ is the average high-resolution sulfatenormalized mass concentration of total organic, and $\mathrm{O} / \mathrm{C}$ and $\mathrm{H} / \mathrm{C}$ are the oxygen-to-carbon and hydrogen-to-carbon ratios, respectively, of the organic species, with the subscripts $i$ and $f$ denoting initial and final conditions (before and after $\mathrm{H}_{2} \mathrm{O}_{2}$ addition), respectively. For example, in the case of erythritol oxidation, $51 \%$ of the initial carbon remained after bulk oxidation, but only $16 \%$ remained after oxidation in aqueous aerosol in the chamber. For all bulk experiments, between 48 and $58 \%$ of the original carbon remained in the condensed phase after oxidation, with no obvious dependence on carbon number. However, a clear trend is observed for the chamber experiments, with $f_{\mathrm{C}}$ increasing with the size of the polyol.

\subsection{Differences between chamber and bulk experiments}

The above observations - that a larger fraction of carbon remains in the condensed phase for the bulk experiments than for the chamber experiments, and that this difference gets smaller with increasing carbon number - can be explained either by differences in reactivity or differences in partitioning between the two systems. The submicron particles in the chamber have higher reactant concentrations and a greater ionic strength than the dilute bulk solution, and also require dissolution of gas-phase $\mathrm{H}_{2} \mathrm{O}_{2}$ prior to oxidation; these differences may cause the observed differences in oxidation kinetics. Furthermore, the availability of gas-phase $\mathrm{H}_{2} \mathrm{O}_{2}$ in the chamber that can partition into the submicron particles could allow for a longer production of $\mathrm{OH}$. However, the ratio of polyol to $\mathrm{Fe}^{2+}$ is also greater in the chamber, so the $\mathrm{OH}$ may react away more quickly. These complex effects are difficult to quantify, but could result in different chemical reactions and degrees of oxidation between the two systems.

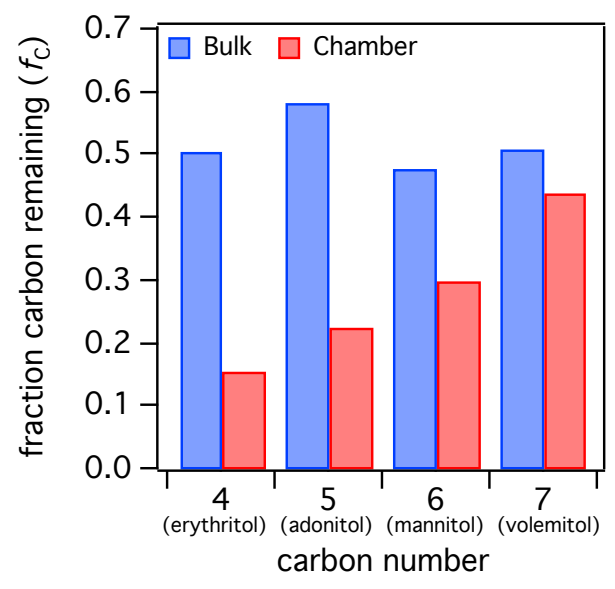

Figure 5. The fraction of carbon remaining in the condensed phase after oxidation $\left(f_{\mathrm{C}}\right)$ in the bulk solution (blue bars) or in submicron particles (red bars), as calculated from Eq. (2), using highresolution V-mode data. Meaningful values could not be determined for the oxidation of glycerol (C3) due to evaporation from the particle phase prior to oxidation.

Nonetheless, it is unlikely that differences in reactivity are driving the differences in $f_{\mathrm{C}}$ between the bulk and chamber experiments, given the similarities in mass spectra, changes to individual ions, and elemental ratios in the two cases (as shown in Figs. 3, 4, and S1-4 in the Supplement). The final $\mathrm{OH}$ exposures for the oxidation of erythritol in the bulk solution $\left(4.7 \times 10^{-12} \mathrm{Ms}\right)$ and in the submicron particles $\left(2.7 \times 10^{-9} \mathrm{M} \mathrm{s}\right)$ agree to within a factor of 2 . This is true for the larger polyols (C5-C7) as well (Fig. S5 in the Supplement), suggesting that differences in oxidant availability are not likely to account for the observed differences between the bulk and chamber results. Furthermore, the variation in $f_{\mathrm{C}}$ for different polyols oxidized in the chamber (Fig. 5) is also unlikely to result from differences in chemistry, given that the oxidation conditions were the same.

Rather, the difference in total organic mass remaining in the condensed phase appears to be a result of differences in gas-aqueous partitioning of intermediate species (earlygeneration oxidation products). A general mechanism is illustrated in Fig. 6. The polyol is oxidized to form multiple generations of products, ultimately forming oxalate (in the form of an iron (III) oxalato complex). In the bulk aqueous solution, where the liquid water content is very high, the reactants, intermediates, and products remain in the condensed phase. (Some of these species may evaporate upon atomization and not be detected by the AMS, but they still would have been present in the condensed phase during oxidation.) However, in the chamber experiments, in which LWC is low, relatively volatile compounds can partition out of the condensed phase. The polyols and oxalate are sufficiently water-soluble to remain in the particle phase at this low LWC, suggesting that the partitioning of intermediate compounds from the aqueous phase to the gas phase (red 


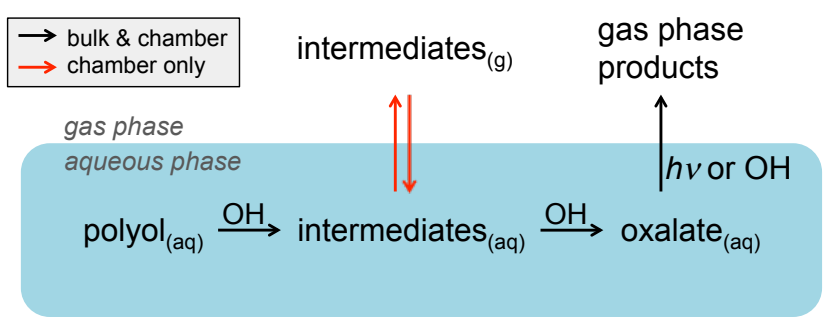

Figure 6. Simplified mechanism to explain observed differences between oxidation in the bulk and in submicron particles. The polyol reacts to form intermediates with lower $H^{*}$ (higher volatility over water), which remain fully in the aqueous phase during bulk experiments, but partition to the gas phase (red arrows) during chamber experiments. This partitioning, which occurs to a greater extent for smaller polyol precursors, competes with further aqueous oxidation, and has the effect of lowering the product (oxalate) yield. Upon exposure to ultraviolet light, the Fe(III) oxalato complex photolyzes, forming small gas-phase products.

arrow in Fig. 6) accounts for the increased loss of organic material in the chamber. These early-generation oxidation products are likely to be more volatile (lower $H^{*}$ ) than the polyol precursor, due to the oxidative conversion of hydroxyl groups to carbonyl groups (Bethel et al., 2003) and/or the formation of smaller molecular species via fragmentation reactions (Kroll et al., 2009). Evaporation of these species may also be promoted by a decrease in particulate water, which is observed upon $\mathrm{H}_{2} \mathrm{O}_{2}$ addition and likely occurs due to a change in the hygroscopicity of iron salts upon initiation of Fenton chemistry. Regardless of the exact mechanism, partitioning of intermediates into the gas phase will compete with further oxidation, as shown in Fig. 6, resulting in lower yields of oxalate than were measured in the bulk experiments. This general mechanism also explains the correlation between $f_{\mathrm{C}}$ and carbon number (Fig. 5), since the size, and thus the volatility, of the intermediate compounds should be related to the size of the polyol precursor.

\section{Conclusions and implications}

To our knowledge, this work presents the first direct comparison of aqueous-phase oxidation within submicron particles to that within the bulk phase. In both systems, dark Fenton chemistry leads to the rapid conversion of polyol precursors to highly oxidized organic material, a result that is broadly consistent with previous aqueous-phase oxidation studies (Altieri et al., 2006, 2008; Carlton et al., 2007; Kirkland et al., 2013; Lee et al., 2011a, b; 2012; Liu et al., 2012a; Nguyen et al., 2013; Perri et al., 2009; Sun et al., 2010; Tan et al., 2009, 2010; Zhang et al., 2010; Zhao et al., 2012). The primary difference between the two systems is that less carbon remains in the condensed phase in the chamber experiments, with the smallest precursors having the greatest differences in $f_{\mathrm{C}}$. As shown in Fig. 1, under bulk conditions, any compound with $H^{*} \gtrsim 0.1 \mathrm{Matm}^{-1}$ should be present primarily in the aqueous phase. However, at the lower LWC of the chamber, compounds with $H^{*}$ as high as $10^{9} \mathrm{M} \mathrm{atm}^{-1}$ will instead be present predominantly in the gas phase. Thus, species with $H^{*}$ between these limits will remain dissolved in bulk-phase water, but will partition out of submicron particles into the gas phase. Our results suggest that the reaction intermediates formed from the oxidation of polyols have $H^{*}$ in this range. Therefore, the partitioning of these earlygeneration products from aqueous aerosol to the gas phase can explain the dramatic differences in $f_{\mathrm{C}}$ observed in the bulk and chamber experiments.

The present results confirm those of previous studies showing that aqueous-phase oxidation is an efficient pathway for the rapid formation of highly oxidized material. However, when oxidation occurs within submicron particles, the fraction of carbon remaining in the condensed phase is substantially smaller than in the bulk oxidation experiments, implying that the formation of highly oxidized OA by aqueous chemistry may be somewhat less important than bulkphase experiments suggest. Bulk oxidation experiments may not accurately simulate the chemistry that takes place in the atmospheric aqueous phase, due to large differences in LWC (and therefore partitioning) between the bulk solution and atmospheric droplets or particles. This difference points to the importance of running aqueous-phase oxidation experiments under atmospherically relevant partitioning conditions. This is analogous to chamber studies of secondary organic aerosol (SOA) formation via partitioning into the condensed-organic phase, which to be representative of atmospheric conditions must be run at low total organic mass concentrations $\left(c_{\mathrm{OA}}\right)$ (Presto and Donahue, 2006). A major difference between such "traditional" SOA chamber experiments and aqueous-phase oxidation, however, is that LWC can vary by a great deal more than $c_{\mathrm{OA}}$ between the laboratory and atmosphere. Our results show that even bulk oxidation experiments that allow for evaporation of oxidation products (Lee et al., 2011a, b, 2012; Liu et al., 2012b; Ortiz-Montalvo et al., 2012; Zhao et al., 2012) may not fully simulate atmospheric processing, since they do not include the effects of partitioning of reaction intermediates. Further, the experiments with glycerol oxidation demonstrate that in bulk-phase experiments it is possible to oxidize compounds that would not actually be present in the atmospheric aqueous phase under most conditions. Results from the oxidation of larger polyols indicate that differences in LWC between bulk and chamber oxidation result in significant differences in partitioning, which in turn can affect the chemistry. For experiments like ours with a single product, this affects only the final yield. However, when multiple oxidation products are formed, with intermediates of varying volatility, changing the LWC may also alter the product distributions.

This study underscores the need for conducting oxidation experiments at atmospherically relevant liquid water contents, and extending the existing suite of bulk experiments 
to additional partitioning conditions. Oxidizing previously studied compounds (small carbonyls, acids, isoprene oxidation products, etc.) within aqueous submicron particles would provide valuable information on the role of partitioning and LWC on the formation of highly oxidized OA for a wider range of water-soluble organic compounds. Further, the large differences in partitioning between deliquesced particles and clouds (Fig. 1) suggest that a similar set of experiments is a useful next step for the accurate study of atmospheric cloud processing. Oxidation experiments involving actual cloud droplets, with LWCs much higher than those of aqueous particles but still far lower than that of the bulk aqueous phase, would improve our understanding of this potentially important source of oxidized organic aerosol.

\section{The Supplement related to this article is available online at doi:10.5194/acp-14-10773-2014-supplement.}

Acknowledgements. This work was supported by the National Science Foundation under grant number AGS-1056225.

Edited by: F. Keutsch

\section{References}

Aiken, A. C., DeCarlo, P. F. and Jimenez, J. L.: Elemental analysis of organic species with electron ionization highresolution mass spectrometry, Anal. Chem., 79, 8350-8358, doi:10.1021/ac071150w, 2007.

Aiken, A. C., DeCarlo, P. F., Kroll, J. H., Worsnop, D. R., Huffman, J. A., Docherty, K. S., Ulbrich, I. M., Mohr, C., Kimmel, J. R., Sueper, D., Sun, Y., Zhang, Q., Trimborn, A., Northway, M., Ziemann, P. J., Canagaratna, M. R., Onasch, T. B., Alfarra, M. R., Prevot, A. S. H., Dommen, J., Duplissy, J., Metzger, A., Baltensperger, U., and Jimenez, J. L.: O/C and OM/OC ratios of primary, secondary, and ambient organic aerosols with highresolution time-of-flight aerosol mass spectrometry, Environ. Sci. Technol., 42, 4478-4485, doi:10.1021/es703009q, 2008.

Altieri, K. E., Carlton, A. G., Lim, H.-J., Turpin, B. J., and Seitzinger, S. P.: Evidence for oligomer formation in clouds: Reactions of isoprene oxidation products, Environ. Sci. Technol., 40, 4956-4960, doi:10.1021/es052170n, 2006.

Altieri, K. E., Seitzinger, S. P., Carlton, A. G., Turpin, B. J., Klein, G. C., and Marshall, A. G.: Oligomers formed through in-cloud methylglyoxal reactions: Chemical composition, properties, and mechanisms investigated by ultra-high resolution FT-ICR mass spectrometry, Atmos. Environ., 42, 1476-1490, doi:10.1016/j.atmosenv.2007.11.015, 2008.

Arakaki, T. and Faust, B. C.: Sources, sinks, and mechanisms of hydroxyl radical $\left({ }^{\circ} \mathrm{OH}\right)$ photoproduction and consumption in authentic acidic continental cloud waters from Whiteface Mountain, New York: The role of the Fe(r) ( $\mathrm{r}=\mathrm{II}, \mathrm{III})$ photochemical cycle, J. Geophys. Res.-Atmos., 103, 3487-3504, doi:10.1029/97JD02795, 1998.
Bethel, H. L., Atkinson, R., and Arey, J.: Hydroxycarbonyl products of the reactions of selected diols with the $\mathrm{OH}$ radical, J. Phys. Chem. A, 107, 6200-6205, doi:10.1021/jp0276931, 2003.

Canagaratna, M. R., Jayne, J. T., Jimenez, J. L., Allan, J. D., Alfarra, M. R., Zhang, Q., Onasch, T. B., Drewnick, F., Coe, H., Middlebrook, A., Delia, A., Williams, L. R., Trimborn, A. M., Northway, M. J., DeCarlo, P. F., Kolb, C. E., Davidovits, P., and Worsnop, D. R.: Chemical and microphysical characterization of ambient aerosols with the aerodyne aerosol mass spectrometer, Mass. Spectrom. Rev., 26, 185-222, doi:10.1002/mas.20115, 2007.

Carlton, A. G., Turpin, B. J., Altieri, K. E., Seitzinger, S., Reff, A., Lim, H.-J., and Ervens, B.: Atmospheric oxalic acid and SOA production from glyoxal: Results of aqueous photooxidation experiments, Atmos. Environ., 41, 7588-7602, doi:10.1016/j.atmosenv.2007.05.035, 2007.

Daumit, K. E., Kessler, S. H., and Kroll, J. H.: Average chemical properties and potential formation pathways of highly oxidized organic aerosol, Faraday Discuss., 165, 181-202, doi:10.1039/c3fd00045a, 2013.

DeCarlo, P. F., Kimmel, J. R., Trimborn, A., Northway, M. J., Jayne, J. T., Aiken, A. C., Gonin, M., Fuhrer, K., Horvath, T., Docherty, K. S., Worsnop, D. R., and Jimenez, J. L.: Field-deployable, high-resolution, time-of-flight aerosol mass spectrometer, Anal. Chem., 78, 8281-8289, doi:10.1021/ac061249n, 2006.

Donahue, N. M., Henry, K. M., Mentel, T. F., Kiendler-Scharr, A., Spindler, C., Bohn, B., Brauers, T., Dorn, H. P., Fuchs, H., Tillmann, R., Wahner, A., Saathoff, H., Naumann, K.-H., Mohler, O., Leisner, T., Muller, L., Reinnig, M.-C., Hoffmann, T., Salo, K., Hallquist, M., Frosch, M., Bilde, M., Tritscher, T., Barmet, P., Praplan, A. P., DeCarlo, P. F., Dommen, J., Prevot, A. S. H., and Baltensperger, U.: Aging of biogenic secondary organic aerosol via gas-phase $\mathrm{OH}$ radical reactions, P. Natl. Acad. Sci. USA, 109, 13503-13508, doi:10.1073/pnas.1115186109, 2012.

Donahue, N. M., Robinson, A. L., Trump, E. R., Riipinen, I., and Kroll, J. H.: Volatility and aging of atmospheric organic aerosol, Top. Curr. Chem., 339, 97-144, doi:10.1007/128_2012_355, 2014.

Dzepina, K., Volkamer, R. M., Madronich, S., Tulet, P., Ulbrich, I. M., Zhang, Q., Cappa, C. D., Ziemann, P. J., and Jimenez, J. L.: Evaluation of recently-proposed secondary organic aerosol models for a case study in Mexico City, Atmos. Chem. Phys., 9, 5681-5709, doi:10.5194/acp-9-5681-2009, 2009.

Dzepina, K., Cappa, C. D., Volkamer, R. M., Madronich, S., DeCarlo, P. F., Zaveri, R. A., and Jimenez, J. L.: Modeling the multiday evolution and aging of secondary organic aerosol during MILAGRO 2006, Environ. Sci. Technol., 45, 3496-3503, doi:10.1021/es103186f, 2011.

Ervens, B., Feingold, G., Frost, G. J., and Kreidenweis, S. M.: A modeling study of aqueous production of dicarboxylic acids: 1 . Chemical pathways and speciated organic mass production, J. Geophys. Res., 109, D15205, doi:10.1029/2003JD004387, 2004.

Ervens, B., Turpin, B. J., and Weber, R. J.: Secondary organic aerosol formation in cloud droplets and aqueous particles (aqSOA): a review of laboratory, field and model studies, Atmos. Chem. Phys., 11, 11069-11102, doi:10.5194/acp-1111069-2011, 2011.

Faust, B. C. and Hoigne, J.: Photolysis of Fe (III)-hydroxy complexes as sources of $\mathrm{OH}$ radicals in clouds, fog and rain, Atmos. 
Environ. A.-Gen., 24, 79-89, doi:10.1016/0960-1686(90)90443Q, 1990.

Galloway, M. M., Chhabra, P. S., Chan, A. W. H., Surratt, J. D., Flagan, R. C., Seinfeld, J. H., and Keutsch, F. N.: Glyoxal uptake on ammonium sulphate seed aerosol: reaction products and reversibility of uptake under dark and irradiated conditions, Atmos. Chem. Phys., 9, 3331-3345, doi:10.5194/acp-9-3331-2009, 2009.

Heald, C. L., Kroll, J. H., Jimenez, J. L., Docherty, K. S., DeCarlo, P. F., Aiken, A. C., Chen, Q., Martin, S. T., Farmer, D. K., and Artaxo, P.: A simplified description of the evolution of organic aerosol composition in the atmosphere, Geophys. Res. Lett., 37, L08803, doi:10.1029/2010GL042737, 2010.

Herrmann, H., Hoffmann, D., Schaefer, T., Bräuer, P., and Tilgner, A.: Tropospheric aqueous-phase free-radical chemistry: Radical sources, spectra, reaction kinetics and prediction tools, Chem. Phys. Chem., 11, 3796-3822, doi:10.1002/cphc.201000533, 2010.

Hodzic, A., Jimenez, J. L., Madronich, S., Canagaratna, M. R., DeCarlo, P. F., Kleinman, L., and Fast, J.: Modeling organic aerosols in a megacity: potential contribution of semi-volatile and intermediate volatility primary organic compounds to secondary organic aerosol formation, Atmos. Chem. Phys., 10, 5491-5514, doi:10.5194/acp-10-5491-2010, 2010.

Hoffmann, P., Dedik, A. N., Ensling, J., Weinbruch, S., Weber, S., Sinner, T., Gütlich, P., and Ortner, H. M.: Speciation of iron in atmospheric aerosol samples, J. Aerosol Sci., 27, 325-337, doi:10.1016/0021-8502(95)00563-3, 1996.

Jimenez, J. L., Canagaratna, M. R., Donahue, N. M., Prevot, A., Zhang, Q., Kroll, J. H., DeCarlo, P. F., Allan, J. D., Coe, H., and $\mathrm{Ng}$, N. L.: Evolution of organic aerosols in the atmosphere, Science, 326, 1525-1529, doi:10.1126/science.1180353, 2009.

Kameel, F. R., Hoffmann, M. R., and Colussi, A. J.: OH RadicalInitiated Chemistry of Isoprene in Aqueous Media. Atmospheric Implications, J. Phys. Chem. A, 117, 5117-5123, doi:10.1021/jp4026267, 2013.

Kirkland, J. R., Lim, Y. B., Tan, Y., Altieri, K. E., and Turpin, B. J.: Glyoxal secondary organic aerosol chemistry: effects of dilute nitrate and ammonium and support for organic radicalradical oligomer formation, Environ. Chem., 10, 158-166, doi:10.1071/EN13074, 2013.

Kroll, J. H., Smith, J. D., Che, D. L., Kessler, S. H., Worsnop, D. R., and Wilson, K. R.: Measurement of fragmentation and functionalization pathways in the heterogeneous oxidation of oxidized organic aerosol, Phys. Chem. Chem. Phys., 11, 8005-8014, doi:10.1039/b905289e, 2009.

Kroll, J. H., Donahue, N. M., Jimenez, J. L., Kessler, S. H., Canagaratna, M. R., Wilson, K. R., Altieri, K. E., Mazzoleni, L. R., Wozniak, A. S., Bluhm, H., Mysak, E. R., Smith, J. D., Kolb, C. E., and Worsnop, D. R.: Carbon oxidation state as a metric for describing the chemistry of atmospheric organic aerosol, Nat. Chem., 3, 133-139, doi:10.1038/nchem.948, 2011.

Lee, A. K., Herckes, P., Leaitch, W. R., Macdonald, A. M., and Abbatt, J.: Aqueous $\mathrm{OH}$ oxidation of ambient organic aerosol and cloud water organics: Formation of highly oxidized products, Geophys. Res. Lett., 38, L11805, doi:10.1029/2011GL047439, 2011a.

Lee, A. K., Zhao, R., Gao, S. S., and Abbatt, J.: Aqueous-phase $\mathrm{OH}$ oxidation of glyoxal: application of a novel analytical ap- proach employing aerosol mass spectrometry and complementary off-line techniques, J. Phys. Chem. A, 115, 10517-10526, doi:10.1021/jp204099g, 2011b.

Lee, A. K. Y., Hayden, K. L., Herckes, P., Leaitch, W. R., Liggio, J., Macdonald, A. M., and Abbatt, J. P. D.: Characterization of aerosol and cloud water at a mountain site during WACS 2010: secondary organic aerosol formation through oxidative cloud processing, Atmos. Chem. Phys., 12, 7103-7116, doi:10.5194/acp-12-7103-2012, 2012.

Lee-Taylor, J., Madronich, S., Aumont, B., Baker, A., Camredon, M., Hodzic, A., Tyndall, G. S., Apel, E., and Zaveri, R. A.: Explicit modeling of organic chemistry and secondary organic aerosol partitioning for Mexico City and its outflow plume, Atmos. Chem. Phys., 11, 13219-13241, doi:10.5194/acp-1113219-2011, 2011.

Lim, Y. B., Tan, Y., Perri, M. J., Seitzinger, S. P., and Turpin, B. J.: Aqueous chemistry and its role in secondary organic aerosol (SOA) formation, Atmos. Chem. Phys., 10, 1052110539, doi:10.5194/acp-10-10521-2010, 2010.

Liu, Y., Monod, A., Tritscher, T., Praplan, A. P., DeCarlo, P. F., Temime-Roussel, B., Quivet, E., Marchand, N., Dommen, J., and Baltensperger, U.: Aqueous phase processing of secondary organic aerosol from isoprene photooxidation, Atmos. Chem. Phys., 12, 5879-5895, doi:10.5194/acp-12-5879-2012, 2012a.

Liu, Y., Siekmann, F., Renard, P., Zein, El, A., Salque, G., Haddad, El, I., Temime-Roussel, B., Voisin, D., Thissen, R., and Monod, A.: Oligomer and SOA formation through aqueous phase photooxidation of methacrolein and methyl vinyl ketone, Atmos. Environ., 49, 123-129, doi:10.1016/j.atmosenv.2011.12.012, 2012b.

Ma, J., Ma, W., Song, W., Chen, C., Tang, Y., Huang, Y., Xu, Y., Zang, L., and Zhao, J.: Fenton degradation of organic pollutants in the presence of low-molecular-weight organic acids: Cooperative effect of quinone and visible light, Environ. Sci. Technol., 40, 618-624, doi:10.1021/es051657t, 2006.

Mensah, A. A., Buchholz, A., Mentel, Th. F., Tillmann, R., and Kiendler-Scharr, A.: Aerosol mass spectrometric measurements of stable crystal hydrates of oxalates and inferred relative ionization efficiency of water, J. Aerosol Sci., 42, 11-19, doi:10.1016/j.jaerosci.2010.10.003, 2011.

Nguyen, T. B., Coggon, M. M., Flagan, R. C., and Seinfeld, J. H.: Reactive Uptake and Photo-Fenton Oxidation of Glycolaldehyde in Aerosol Liquid Water, Environ. Sci. Technol., 47, 4307-4316, doi:10.1021/es400538j, 2013.

Nozière, B., Dziedzic, P., and Córdova, A.: Products and Kinetics of the Liquid-Phase Reaction of Glyoxal Catalyzed by Ammonium Ions $\left(\mathrm{NH}_{4}^{+}\right)$, J. Phys. Chem. A, 113, 231-237, doi:10.1021/jp8078293, 2009.

Ortiz-Montalvo, D. L., Lim, Y. B., Perri, M. J., Seitzinger, S. P., and Turpin, B. J.: Volatility and yield of glycolaldehyde SOA formed through aqueous photochemistry and droplet evaporation, Aerosol Sci. Tech., 46, 1002-1014, doi:10.1080/02786826.2012.686676, 2012.

Ou, X., Quan, X., Chen, S., Zhang, F., and Zhao, Y.: Photocatalytic reaction by $\mathrm{Fe}$ (III)-citrate complex and its effect on the photodegradation of atrazine in aqueous solution, J. Photoch. Photobio. A, 197, 382-388, doi:10.1016/j.jphotochem.2008.02.001, 2008 . 
Perri, M. J., Seitzinger, S., and Turpin, B. J.: Secondary organic aerosol production from aqueous photooxidation of glycolaldehyde: Laboratory experiments, Atmos. Environ., 43, 1487-1497, doi:10.1016/j.atmosenv.2008.11.037, 2009.

Perri, M. J., Lim, Y. B., Seitzinger, S. P., and Turpin, B. J.: Organosulfates from glycolaldehyde in aqueous aerosols and clouds: Laboratory studies, Atmos. Environ., 44, 2658-2664, doi:10.1016/j.atmosenv.2010.03.031, 2010.

Presto, A. A. and Donahue, N. M.: Investigation of $\alpha$-pinene + ozone secondary organic aerosol formation at low total aerosol mass, Environ. Sci. Technol., 40, 3536-3543, doi:10.1021/es052203z, 2006.

Qi, L., Nakao, S., Malloy, Q., Warren, B., and Cocker III, D. R.: Can secondary organic aerosol formed in an atmospheric simulation chamber continuously age?, Atmos. Environ., 44, 29902996, doi:10.1016/j.atmosenv.2010.05.020, 2010.

Renard, P., Siekmann, F., Gandolfo, A., Socorro, J., Salque, G., Ravier, S., Quivet, E., Clément, J.-L., Traikia, M., Delort, A.M., Voisin, D., Vuitton, V., Thissen, R., and Monod, A.: Radical mechanisms of methyl vinyl ketone oligomerization through aqueous phase $\mathrm{OH}-\mathrm{oxidation}$ : on the paradoxical role of dissolved molecular oxygen, Atmos. Chem. Phys., 13, 6473-6491, doi:10.5194/acp-13-6473-2013, 2013.

Sander, R.: Compilation of Henry's law constants for inorganic and organic species of potential importance in environmental chemistry, (Version 3), available at: http://www.henrys-law.org (last access: September 2014), 1999.

Seinfeld, J. H. and Pandis, S. N.: Atmospheric Chemistry and Physics: From Air Pollution to Climate Change, 2nd Edition, John Wiley \& Sons, Inc., Hoboken, New Jersey, 2006.

Smith, J., Sio, V., Yu, L., Zhang, Q., and Anastasio, C.: Secondary Organic Aerosol Production from Aqueous Reactions of Atmospheric Phenols with an Organic Triplet Excited State, Environ. Sci. Technol., 48, 1049-1057, doi:10.1021/es4045715, 2014.

Sorooshian, A., Wang, Z., Coggon, M. M., Jonsson, H. H., and Ervens, B.: Observations of Sharp Oxalate Reductions in Stratocumulus Clouds at Variable Altitudes: Organic Acid and Metal Measurements During the 2011 E-PEACE Campaign, Environ. Sci. Technol., 47, 7747-7756, doi:10.1021/es4012383, 2013.

Southworth, B. A. and Voelker, B. M.: Hydroxyl radical production via the photo-Fenton reaction in the presence of fulvic acid, Environ. Sci. Technol., 37, 1130-1136, doi:10.1021/es0207571, 2003.

Sun, Y. L., Zhang, Q., Anastasio, C., and Sun, J.: Insights into secondary organic aerosol formed via aqueous-phase reactions of phenolic compounds based on high resolution mass spectrometry, Atmos. Chem. Phys., 10, 4809-4822, doi:10.5194/acp-104809-2010, 2010.
Takegawa, N., Miyakawa, T., Kawamura, K., and Kondo, Y.: Contribution of selected dicarboxylic and $\omega$-oxocarboxylic acids in ambient aerosol to the $\mathrm{m} / \mathrm{z} 44$ signal of an Aerodyne aerosol mass spectrometer, Aerosol Sci. Tech., 41, 418-437, doi:10.1080/02786820701203215, 2007.

Tan, Y., Perri, M. J., Seitzinger, S. P., and Turpin, B. J.: Effects of Precursor Concentration and Acidic Sulfate in Aqueous Glyoxal- OH Radical Oxidation and Implications for Secondary Organic Aerosol, Environ. Sci. Technol., 43, 8105-8112, doi:10.1021/es901742f, 2009.

Tan, Y., Carlton, A. G., Seitzinger, S. P., and Turpin, B. J.: SOA from methylglyoxal in clouds and wet aerosols: Measurement and prediction of key products, Atmos. Environ., 44, 5218-5226, doi:10.1016/j.atmosenv.2010.08.045, 2010.

Tilgner, A. and Herrmann, H.: Radical-driven carbonyl-to-acid conversion and acid degradation in tropospheric aqueous systems studied by CAPRAM, Atmos. Environ., 44, 5415-5422, doi:10.1016/j.atmosenv.2010.07.050, 2010.

Volkamer, R., Jimenez, J. L., San Martini, F., Dzepina, K., Zhang, Q., Salcedo, D., Molina, L. T., Worsnop, D. R., and Molina, M. J.: Secondary organic aerosol formation from anthropogenic air pollution: Rapid and higher than expected, Geophys. Res. Lett., 33, L17811, doi:10.1029/2006GL026899, 2006.

Volkamer, R., Ziemann, P. J., and Molina, M. J.: Secondary Organic Aerosol Formation from Acetylene $\left(\mathrm{C}_{2} \mathrm{H}_{2}\right)$ : seed effect on SOA yields due to organic photochemistry in the aerosol aqueous phase, Atmos. Chem. Phys., 9, 1907-1928, doi:10.5194/acp9-1907-2009, 2009.

Zhang, X., Chen, Z. M., and Zhao, Y.: Laboratory simulation for the aqueous $\mathrm{OH}$-oxidation of methyl vinyl ketone and methacrolein: significance to the in-cloud SOA production, Atmos. Chem. Phys., 10, 9551-9561, doi:10.5194/acp-10-9551-2010, 2010.

Zhao, R., Lee, A., and Abbatt, J.: Investigation of aqueous-phase photooxidation of glyoxal and methylglyoxal by aerosol chemical ionization mass spectrometry: observation of hydroxyhydroperoxide formation, J. Phys. Chem. A, 116, 6253-6263, doi:10.1021/jp211528d, 2012.

Zuo, Y. and Hoigne, J.: Formation of hydrogen peroxide and depletion of oxalic acid in atmospheric water by photolysis of iron (III)-oxalato complexes, Environ. Sci. Technol., 26, 1014-1022, doi:10.1021/es00029a022, 1992. 